\title{
Prognostic Value of Residual Syntax Score after Percutaneous Coronary Intervention in Multivessel Coronary Artery Disease
}

\author{
Sunitha Aramalla $\quad$ Indrani Garre ${ }^{1} \quad$ Shabbir Ali Shaik ${ }^{1} \quad$ P. Hemanth Harish ${ }^{1}$ \\ ${ }^{1}$ Department of Cardiology, NIMS, Punjagutta, Hyderabad, \\ Telangana, India \\ Address for correspondence Sunitha Aramalla, MD, Department of \\ Cardiology, NIMS, Punjagutta, Hyderabad, Telangana -500082, India \\ (e-mail: Sunitha.aramalla@gmail.com).
}

Ind J Car Dis Wom 2019;4:133-141

\begin{abstract}
Background Residual SYNTAX (Synergy between Percutaneous Coronary Intervention with Taxus and Cardiac Surgery) Score (RSS) is an objective measure for the assessment of degree and complexity of residual stenosis after the percutaneous coronary intervention (PCI).

Aim The study aimed at evaluating the role of angiographic complete (CR) and incomplete (ICR) revascularization on clinical outcomes in patients undergoing $\mathrm{PCl}$ for multivessel coronary artery disease (MVCAD). The study sought to investigate the role of initial and residual severity of coronary atherosclerosis in prognostication of patients with MVCAD who underwent PCI.

Material and Methods We retrospectively recruited 135 patients having MVCAD who underwent $\mathrm{PCl}$. Coronary angiogram was used to assess the severity of coronary atherosclerosis. From the angiographic data baseline (BSS) and RSS were calculated. Subjects having a RSS of 0 were defined as having CR, and those having RSS $>0$ are defined as ICR group. The study population was subgrouped into two groups as follows: CR, $0(n=17,23 \%)$; ICR, $>0$ to $4(n=89,47.2 \%)$. Clinical outcomes were measured, which included major adverse cardiac and cerebrovascular events (MACE) at 1 year.

Results Among the study subjects mean age was $57.25 \pm 17.55$. About $76.3 \%$ were males, and $23.7 \%$ were females. About $89.4 \%$ had diabetes, $88.6 \%$ had hypertension as risk factors, and $95.8 \%$ were smokers.

The mean values of BSS and RSS were $20.2 \pm 9.2$ and $4.1 \pm 7.0$, respectively. Based on RSS the individuals were divided into two groups as follows: CR, 0 ( $n=17,23 \%)$; ICR, $>0$ to $4(n=89,47.2 \%),>4$ to $8(n=16,21.6 \%),>8(n=13,17.55 \%)$. After 1 year, three patients lost the follow-up. Among the remaining 132 patients, those with higher BSS had more mortality and morbidity, and the difference is statistically significant

Keywords

- residual SYNTAX Score (RSS)

- multivessel coronary artery disease (MVCAD)

- complete revascularization (CR)

- incomplete revascularization (ICR) (MACE in $\geq 23$ vs. $<23, p=0.000755$ ); 10 patients in the ICR group had MACE compared with 1 patient in CR group(5.8\% in CR group vs. $8.6 \%$ in ICR group, $p$-value of 0.38 ); however, the difference was not statistically significant. However, higher RSS acts as an indirect marker of increasing morbidity and mortality when compared within the tertiles, and the difference was statistically significant (RSS 1-4 group vs. > 4 MACE, $p=0.0009559$, RSS < 8 vs. $>8$ MACE, $p=0.00000172$ ).

Conclusions This study proved that both BSS and higher RSS help to foretell the risk of adverse clinical outcomes in individuals with MVCAD who underwent PCI. RSS, which is an indirect marker of residual atherosclerosis, that is, ICR, had a positive correlation MACE after $\mathrm{PCI}$.
\end{abstract}

published online December 2, 2019
DOI https://doi.org/ 10.1055/s-0039-3400204
C02019 Women in Cardiology and Related Sciences
License terms

(ㅇ)(1) $\odot \circledast$ 


\section{Introduction}

In patients with multivessel coronary artery disease (MVCAD), residual SYNTAX (Synergy between Percutaneous Coronary Intervention with Taxus and Cardiac Surgery) Score (RSS) has been shown to be a marker of the residual anatomic coronary atherosclerotic plaque burden and clinical comorbidity in patients undergoing revascularization (percutaneous or surgical) in a post-hoc analysis ${ }^{1}$ of the SYNTAX trial. ${ }^{2-5}$ Incomplete revascularization (ICR) has been linked to the adverse clinical outcome on the short-term and long-term follow-up as shown by many studies. ${ }^{6-14}$ The theory of reasonable ICR has been proposed that is a clinical dictator of the acceptable burden of residual atherosclerotic plaque burden, post-revascularization in whom CR was could not need to be done. ${ }^{7,8,11,13,15}$ RSS is an objective and quantitative parameter, measures residual anatomic coronary atherosclerotic plaque burden and the complexity of coronary anatomy after the percutaneous coronary intervention (PCI). ${ }^{16}$ The objective of this study was to assess the application of RSS in prognostication in MVCAD patients at 1-year follow-up post-PCI.

\section{Materials and Methods}

After informed consent, a total of 135 patients were recruited retrospectively from our unit PCI registry. Those patients who were having MVCAD and underwent PCI were included. Exclusion criteria included subjects with prior coronary revascularization, and those subjects with a requirement of concomitant cardiac surgery (e.g., resection of aortic or left ventricular (LV) aneurysm, and valve surgery). We noted the demographic data (age, sex, socioeconomic status), risk factors (diabetic status hypertension, smoking), clinical presentation, laboratory parameters (electrocardiogram, echocardiogram, complete blood picture, liver function tests, serum electrolytes, renal function tests), and CAG findings in patients having MVCAD who underwent PCI. After coronary angiography, the severity of coronary atherosclerosis was assessed using the SYNTAX score. After PCI, the RSS was calculated to all the subjects. All the subjects with RSS of $<0$ were considered as CR group, and those with RSS $>0$ were considered as ICR group who were further classified to tertiles of RSS 0 to 4,4 to 8 , and $>8$. After 1 year, clinical outcomes were assessed.

\section{Results}

Among the total 135 patients, the mean age was $57.25 \pm 17.55,76.3 \%$ were males, and $23.7 \%$ were females. Diabetes is observed in $89.4 \%$, hypertension is observed in $88.6 \%$, smoking is observed in $95.8 \%$. Baseline SYNTAX Score (BSS) and RSS were calculated. The mean values of BSS and RSS were $20.2 \pm 9.2$ and $4.1 \pm 7.0$, respectively. Based on RSS, the individuals were divided into two groups as follows: CR, 0 ( $n=17,23 \%)$; ICR, $>0$ to 4 ( $n=89,47.2 \%),>4$ to $8(n=16,21.6 \%),>8(n=13,17.55 \%)$. After a follow-up of 1 year, three patients lost to follow-up. The distribution of clinical and angiographic profiles is shown in - Table 1
The details are described in the following tables (-Tables 1-6).

Among the remaining 132 patients, patients with higher BSS had more mortality and morbidity (major adverse cardiac and cerebrovascular events [MACE] in $\geq 23$ vs. $<23, p=0.000755$ ); 10 patients in the ICR group had MACE compared with one patient in $\mathrm{CR}$ group(5.8\% in CR group vs. $8.6 \%$ in ICR group, $p$-value of 0.38 ) the difference of which was not statistically significant. Out of 135 patients, 75.5\% (102) cases were men, and 24.5\% (33) cases were women; MACE events were compared that showed $p$-value of 0.075 , which is not significant. The occurrence of various risk factors predicting the occurrence of higher RSS like diabetes $(p=0.14)$, hypertension $(p=0.22)$, smoking $(p=0.08)$, LV dysfunction ( $p=0.17)$, type of CAD $(p=0.15)$, and higher body mass index $(p=0.12)$ was not statistically significant. Presence of lesional calcification $(p=0.49)$ and presence of ostial disease $(p=0.09)$ are shown in - Table1 - Figs. 1 to 7 .

-Figs. 1 to 3 show the distribution of risk factors such as hypertension, diabetes, and smoking among the study population. There is no statistically significant difference observed in the distribution of risk factors among CR versus ICR group.

-Figure 4 shows the distribution of echocardiographically observed LV dysfunction among the study population. There is no statistically significant difference observed in the distribution of LV dysfunction among CR versus ICR group.

-Figure 5 shows the distribution of clinical presentations, such as acute coronary syndrome versus chronic stable angina among the study population. There is no statistically significant difference observed in the type of clinical presentation among $\mathrm{CR}$ versus ICR group.

- Figs. 6 and 7 show the distribution of angiographic plaque characteristics such as lesional calcification and coronary ostial disease among the study population, which showed no statistically significant difference among CR versus ICR group.

The occurrence of MACE when compared within BSS $<23$ versus BSS $>23$ showed a statistically significant difference with a $p$-value of 0.0007558 , as shown in - Table 2 - Fig. 8 .

Distribution of study population among post-PCI patients with RSS $=0$ and RSS $>0$, that is, CR versus ICR groups and the MACE in the individual group is shown in and - Tables 3 and 4 -Figs. 9 and 10, which show that higher number of MACE occurred in patients with high RSS; however, the difference was not statistically significant with a $p$-value of 0.38 . The distribution of RSS across tertiles of the study population is described in - Fig. $\mathbf{9}$.

Distribution of study population among different RSS groups and the MACE in the individual group is shown in - Tables 5 and 6. These results showed that as the RSS is increasing, there is a higher chance for MACE, statistically significant difference observed when RSS 1 to 4 was compared with RSS $>4 \quad p$-values was 0.0009559 , and RSS $<8$ compared with $\mathrm{v}>8$ p-values was 0.00000172 .

\section{Discussion}

The present study showed that anatomical residual coronary artery disease is helping to predict MACE during follow-up of post-PCI patients. This is also shown in many trials such as 
Table 1 Clinical and angiographic parameters

\begin{tabular}{|c|c|c|c|c|}
\hline Parameter & Total & RSS $=0$ & RSS $>0$ & $p$-Value \\
\hline & $(n=135)$ & $(n=17)$ & $(n=118)$ & \\
\hline Age & $57.25 \pm 17.55$ & $55.69 \pm 14.926$ & $57.69 \pm 17.7$ & 0.61 \\
\hline \multicolumn{5}{|l|}{ Gender } \\
\hline Male & $102(76 \%)$ & $12(70.5 \%)$ & $90(76.3 \%)$ & \multirow[t]{2}{*}{0.61} \\
\hline Female & $33(24 \%)$ & $5(29 \%)$ & $28(23.7 \%)$ & \\
\hline \multicolumn{5}{|l|}{ Diabetes } \\
\hline Yes & $95(72.4 \%)$ & $10(10.5 \%)$ & 85 (89.4\%) & \multirow[t]{2}{*}{0.14} \\
\hline No & $40(29.6 \%)$ & $7(17.5 \%)$ & $33(82.5 \%)$ & \\
\hline \multicolumn{5}{|l|}{ Hypertension } \\
\hline Yes & $105(77.7 \%)$ & $12(11.4 \%)$ & $93(88.6 \%)$ & \multirow[t]{2}{*}{0.22} \\
\hline No & $30(22.2 \%)$ & $5(16.6 \%)$ & $25(83.4 \%)$ & \\
\hline \multicolumn{5}{|l|}{ Current smoking } \\
\hline Yes & $24(17.7 \%)$ & $1(4.1 \%)$ & $23(95.8 \%)$ & \multirow[t]{2}{*}{0.08} \\
\hline No & $111(82.3 \%)$ & $16(14.4 \%)$ & 95 (85.5\%) & \\
\hline \multicolumn{5}{|l|}{ LV function } \\
\hline Good & $98(72.5 \%)$ & $14(14.2 \%)$ & $84(85.7 \%)$ & \multirow[t]{4}{*}{0.17} \\
\hline Mild dysfunction & $18(13.3 \%)$ & $1(5.5 \%)$ & $17(94.5 \%)$ & \\
\hline Moderate dysfunction & $11(8.1 \%)$ & $1(9.09 \%)$ & $10(90.9 \%)$ & \\
\hline Severe dysfunction & $8(5.9 \%)$ & $1(12.5 \%)$ & $7(98.75 \%)$ & \\
\hline \multicolumn{5}{|l|}{ Type of CAD } \\
\hline ACS & $48(35.5 \%)$ & $8(16.6 \%)$ & $40(83.3 \%)$ & \multirow[t]{2}{*}{0.15} \\
\hline CSA & 87 (64.5\%) & $9(10.3 \%)$ & $78(89.6 \%)$ & \\
\hline \multicolumn{5}{|l|}{ BMI } \\
\hline Normal & $86(63.7 \%)$ & $13(15.1 \%)$ & $73(84.9 \%)$ & \multirow[t]{4}{*}{0.12} \\
\hline Overweight & $42(31.1 \%)$ & $4(9.5 \%)$ & $38(90.5 \%)$ & \\
\hline Obese & $6(4.4 \%)$ & $0(0 \%)$ & $6(100 \%)$ & \\
\hline Underweight & $1(0.74 \%)$ & $0(0 \%)$ & $1(100 \%)$ & \\
\hline \multicolumn{5}{|l|}{ Lesional calcification } \\
\hline Yes & $32(23.8 \%)$ & $4(12.5 \%)$ & $28(87.5 \%)$ & \multirow[t]{2}{*}{0.49} \\
\hline No & $103(76.2 \%)$ & $13(12.6 \%)$ & $90(87.4 \%)$ & \\
\hline \multicolumn{5}{|l|}{ Ostial disease } \\
\hline Yes & $12(8.9 \%)$ & $0(0 \%)$ & $12(100 \%)$ & \multirow[t]{2}{*}{0.09} \\
\hline No & $123(91.1 \%)$ & $17(13.8 \%)$ & $106(86.2 \%)$ & \\
\hline \multicolumn{5}{|l|}{ Predilatation } \\
\hline Done & 87 (64.5\%) & $12(13.8 \%)$ & $75(86.2 \%)$ & \multirow[t]{2}{*}{0.42} \\
\hline Not done & $48(38.5 \%)$ & $6(12.5 \%)$ & $42(87.5 \%)$ & \\
\hline Stent diameter & $2.8 \pm 0.7$ & $2.9 \pm 0.4$ & $2.86 \pm 0.26$ & \\
\hline Stent length & $22 \pm 14.4$ & $22 \pm 15.4$ & $21 \pm 14.4$ & \\
\hline \multicolumn{5}{|l|}{ GpllbIlla inhibitor usage } \\
\hline Yes & $23(17 \%)$ & $4(17.4 \%)$ & $19(82.6 \%)$ & \multirow[t]{2}{*}{0.22} \\
\hline No & $112(83 \%)$ & $13(11.6 \%)$ & $99(88.4 \%)$ & \\
\hline BSS & $20.2 \pm 9.2$ & $18.6 \pm 7.3$ & $20.47 \pm 9.4$ & \\
\hline RSS & $4.1 \pm 7.0$ & 0 & $4.7 \pm 6.8$ & \\
\hline
\end{tabular}

Abbreviations: BSS, Baseline SYNTAX Score; CAD, coronary artery disease; Gpllbllla, glycoprotein IIb/Illa inhibitors; LV, left ventricular; RSS, Residual SYNTAX Score. 
Table 2 MACE events, according to BSS

\begin{tabular}{|l|l|l|l|}
\hline $\begin{array}{l}\text { Baseline SYNTAX } \\
\text { score (BSS) }\end{array}$ & MACE+ & MACE- & $p$-Value \\
\hline$<23(n=105)$ & 3 & 102 & \\
\hline$>23(n=30)$ & 8 & 22 & \\
\hline & 11 & 124 & 0.0007558 \\
\hline
\end{tabular}

Abbreviations: BSS, Baseline SYNTAX Score; MACE, major adverse cardiac and cerebrovascular events.

Table 3 MACE according to RSS

\begin{tabular}{|l|l|l|l|}
\hline Event & Total $(\boldsymbol{n}=135)$ & RSS $=\mathbf{0}$ & RSS > 0 \\
\hline Asymptomatic & $121(89.6 \%)$ & $16(13.2 \%)$ & $105(77.8 \%)$ \\
\hline Angina & $9(6.6 \%)$ & $1(11.1 \%)$ & $8(88.9 \%)$ \\
\hline Death & $2(1.5 \%)$ & $0(0 \%)$ & $2(100 \%)$ \\
\hline No response & $3(2.2 \%)$ & $0(0 \%)$ & $3(100 \%)$ \\
\hline
\end{tabular}

Abbreviations: MACE, major adverse cardiac and cerebrovascular events; RSS, Residual SYNTAX Score.

Table 4 MACE as per different tertiles on ICR group

\begin{tabular}{|l|l|l|l|}
\hline Responders $(\boldsymbol{n}=132)$ & MACE + & MACE- & $p$-Value \\
\hline CR, $n=17$ & $1(5.88 \%)$ & $16(94.1 \%)$ & 0.49 \\
\cline { 1 - 2 } ICR, $n=115$ & $10(8.6 \%)$ & $\begin{array}{l}105 \\
(91.4 \%)\end{array}$ & \\
\hline & 11 & 121 & \\
\hline
\end{tabular}

Abbreviations: CR, complete revascularization; ICR, incomplete revascularization; MACE, major adverse cardiac and cerebrovascular events.

Table 5 Different types of MACE, according to RSS

\begin{tabular}{|l|l|l|l|l|l|}
\hline RSS & $\boldsymbol{n}=\mathbf{1 3 5}$ & Angina & Death & Nonresponders & $\begin{array}{l}\text { MACE } \\
\text { no. }\end{array}$ \\
\hline 0 & 17 & 1 & 0 & 0 & 1 \\
\hline $1-4$ & 89 & 2 & 0 & 2 & 2 \\
\hline $\begin{array}{l}>4- \\
8\end{array}$ & 16 & 1 & 0 & 0 & 1 \\
\hline$>8$ & 13 & 5 & 2 & 1 & 7 \\
\hline $\begin{array}{l}\text { To- } \\
\text { tal }\end{array}$ & 135 & 9 & 2 & 3 & 11 \\
\hline
\end{tabular}

Abbreviations: MACE, major adverse cardiac and cerebrovascular events; RSS, Residual SYNTAX Score.

Table 6 MACE in responder population

\begin{tabular}{|c|c|c|c|}
\hline ICR & \multirow[t]{2}{*}{ MACE+ } & \multirow[t]{2}{*}{ MACE- } & \multirow[t]{2}{*}{$p$-Value } \\
\hline $\begin{array}{c}n=118 \text { ( } 3 \text { are } \\
\text { nonresponders) }\end{array}$ & & & \\
\hline RSS1-4 $(n=89)$ & \multirow[t]{2}{*}{2} & \multirow[t]{2}{*}{85} & \multirow[t]{2}{*}{0.0008623} \\
\hline (2 are nonresponders) & & & \\
\hline RSS 4-8 $(n=16)$ & 1 & 15 & 0.00000097 \\
\hline RSS $>8(n=13)$ & \multirow[t]{2}{*}{7} & \multirow[t]{2}{*}{5} & \\
\hline (1 is nonresponders) & & & \\
\hline
\end{tabular}

Abbreviations: ICR, incomplete revascularization; MACE, major adverse cardiac and cerebrovascular events; RSS, Residual SYNTAX Score.
PRAMI (Preventive Angioplasty in Myocardial Infarction), ${ }^{17}$ CVLPRIT (Complete versus Lesion-Only Primary PCI Trial), ${ }^{18}$ and DANAMI-3 PRIMULTI ${ }^{19}$ the authors demonstrated that occurrence of MACE was a positively correlated with higher residual coronary artery disease that is objectively assessed using RSS.

In patients with MVCAD after undergoing PCI the residual plaque burden either obstructive or nonobstructive was associated with more adverse clinical outcomes and affecting the quality of life..$^{20,21}$ Taking this into consideration, the RSS which is an objective measure of the residual plaque burden after PCI retains the value as a measure of the unaddressed anatomic coronary atherosclerotic disease burden that may declare future cardiovascular events.

Patients with elevated RSS were having more comorbidities and elderly compared with others; however, ICR is found to be an independent indicator of MACE during follow-up. Results of the present study have similarity with data published previously, ${ }^{622-24}$ suggesting that amount of anatomical residual atherosclerotic plaque burden, which is objectively reflected by a higher RSS $>8$ after PCI, is associated with worse clinical outcomes in MVCAD patients who underwent $\mathrm{PCI}$. This higher risk could be explained by the fact that patients with high RSS had a large extent of myocardium that is jeopardized or ischemic and overall vascular burden, which is high in these patients. In contrast, to the above findings, patients who had complete anatomical revascularization as evidenced by a lower RSS had the excellent prognosis at follow-up..$^{10,18}$ Thus, decreasing the amount of residual plaque burden that reduces the ischemic burden to the patient would improve the overall long-term prognosis, as shown by many studies correlating survival benefit in patients with inducible ischemia who underwent revascularization. ${ }^{25-27}$

These results were challenging the interventional cardiologist while treating highly complex MVCAD in terms of addressing the entire coronary plaque burden.

Many compared the outcomes between CR versus ICR after PCI. A meta-analysis from nine studies by Aggarwal et al showed that less residual plaque burden following PCI was in line with a lower rate of death, myocardial infarction, and need for coronary artery bypass grafting at a mean follow-up of 29 months. ${ }^{28}$ Another study by Head et $\mathrm{al}^{29}$ investigated the impact of complete versus ICR on 3-year patient outcomes in the SYNTAX trial who declared that CR group had less number of MACE on follow-up. Consistent with the above studies, our study demonstrated that ICR occurred more frequently in patients with more complex coronary artery disease at baseline (total occlusions, more significant number of lesions), which occupied the highest tertile ( $>23$ ) of the BSS.

Advances in PCI technology, with more easily deliverable newer generation drug-eluting Stents and newer adjunctive devices Systems which help in crossing of chronic total occlusions. Imaging technology like intravascular ultrasound, optical coherence tomography that provides guidance to interventional cardiologist to ensure stent optimization, helps in addressing the concept of ICR. Skilled and dedicated cardiologists who can tackle such complex coronary lesions and well-equipped hospital infrastructure help in ensuring full revascularization of 


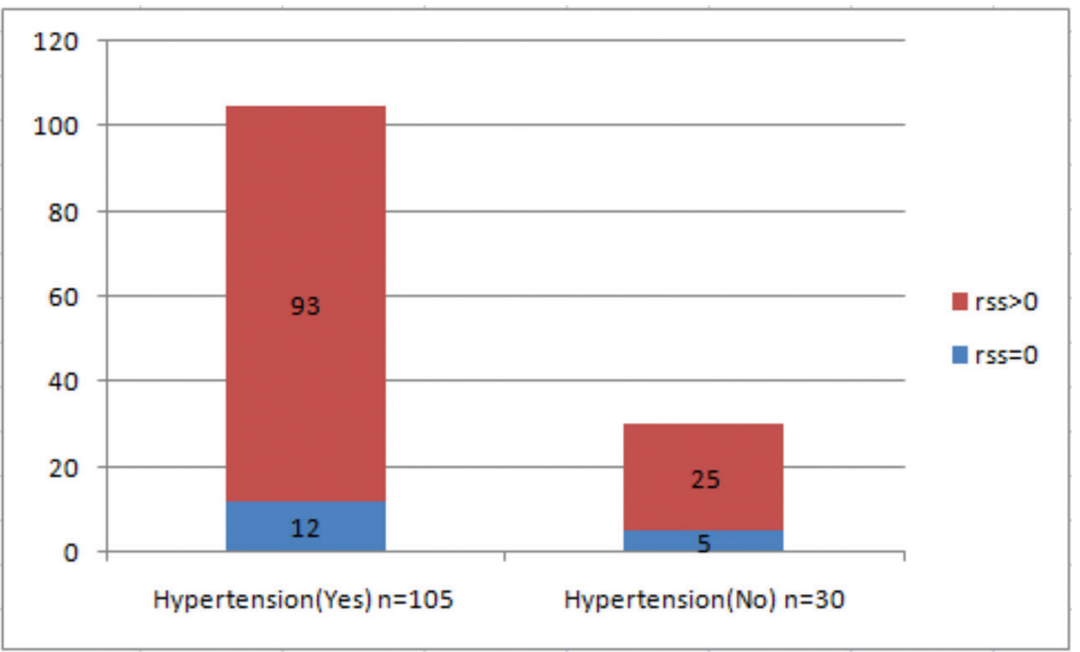

Fig. 1 Hypertension as a risk factor (CR vs. ICR group, $p$-value = 0.22). CR, complete revascularization; ICR, incomplete revascularization; RSS, residual SYNTAX Score.

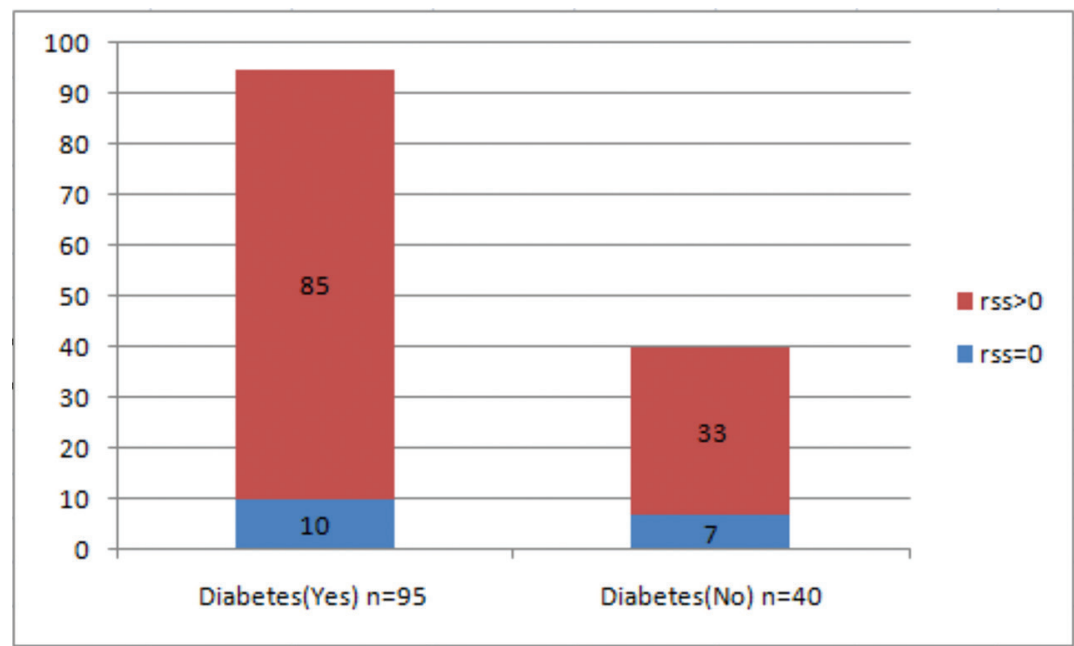

Fig. 2 Diabetes as a risk factor $(C R$ vs. ICR group, $p$-value $=0.14) . C R$, complete revascularization; ICR, incomplete revascularization; RSS, residual SYNTAX Score.

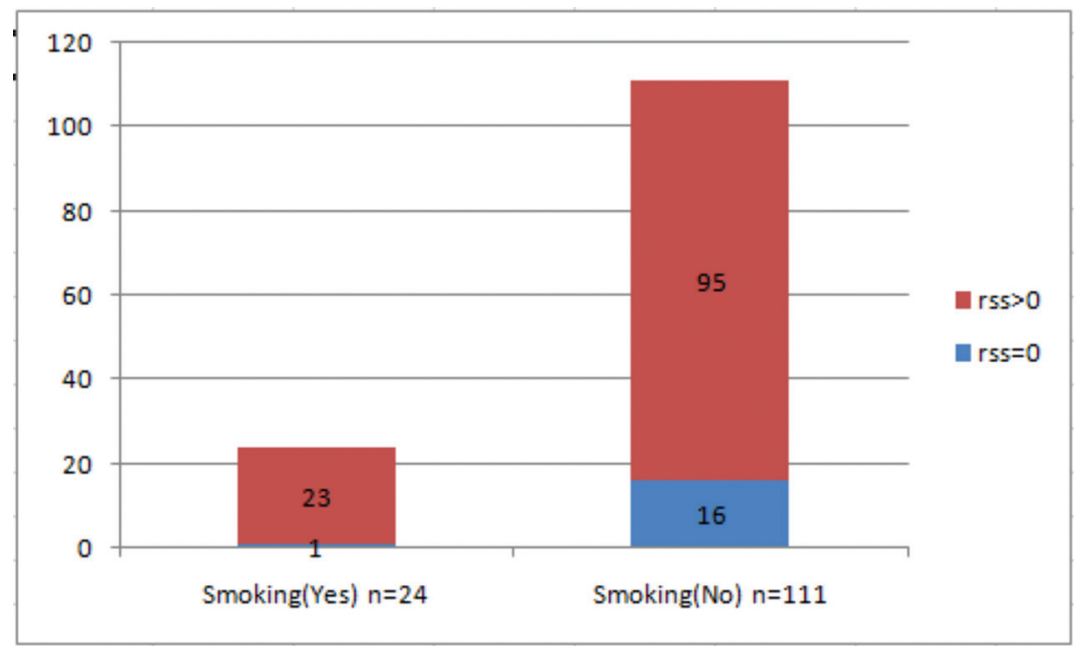

Fig. 3 Smoking as a risk factor (CR vs. ICR group, $p$-value $=0.08) . C R$, complete revascularization; ICR, incomplete revascularization; RSS, residual SYNTAX Score. 


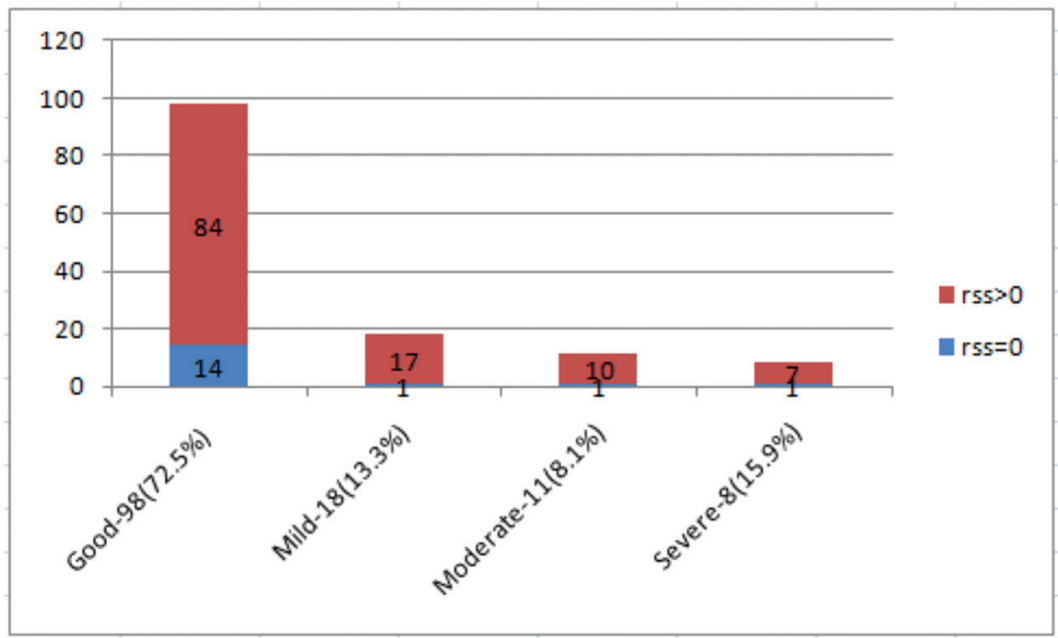

Fig. 4 Left ventricular dysfunction as a risk factor (CR vs. ICR group, $p$-value $=0.17)$. CR, complete revascularization; ICR, incomplete revasCularization; RSS, residual SYNTAX Score.

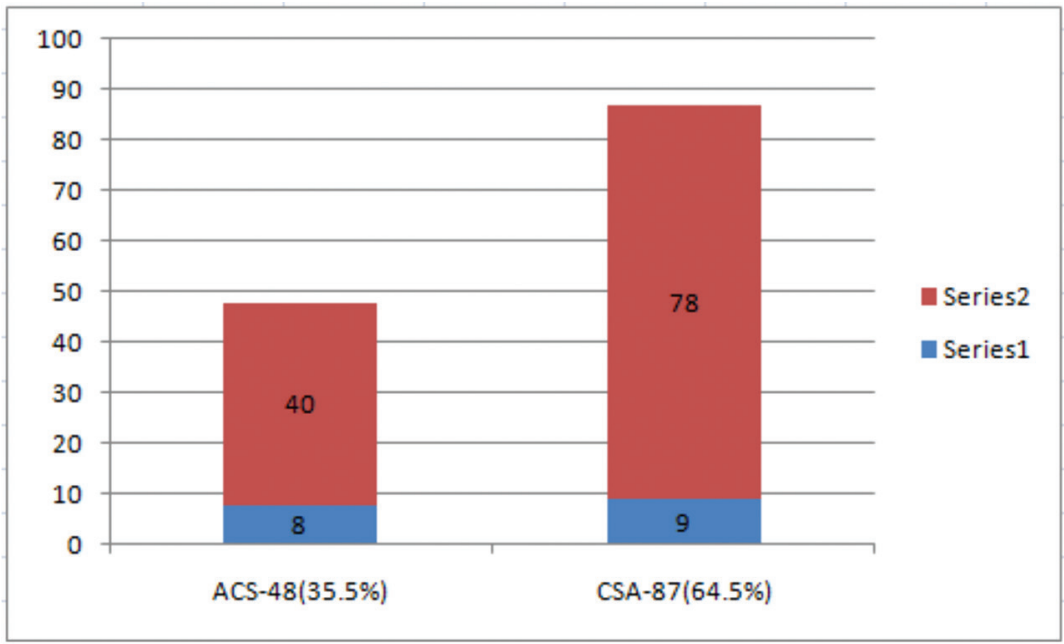

Fig. 5 Type of CAD as a risk factor (CR vs. ICR group, $p$-value = 0.15). ACS, CAD, coronary artery disease; $C R$, complete revascularization; $C S A$, ICR, incomplete revascularization; RSS, residual SYNTAX Score.

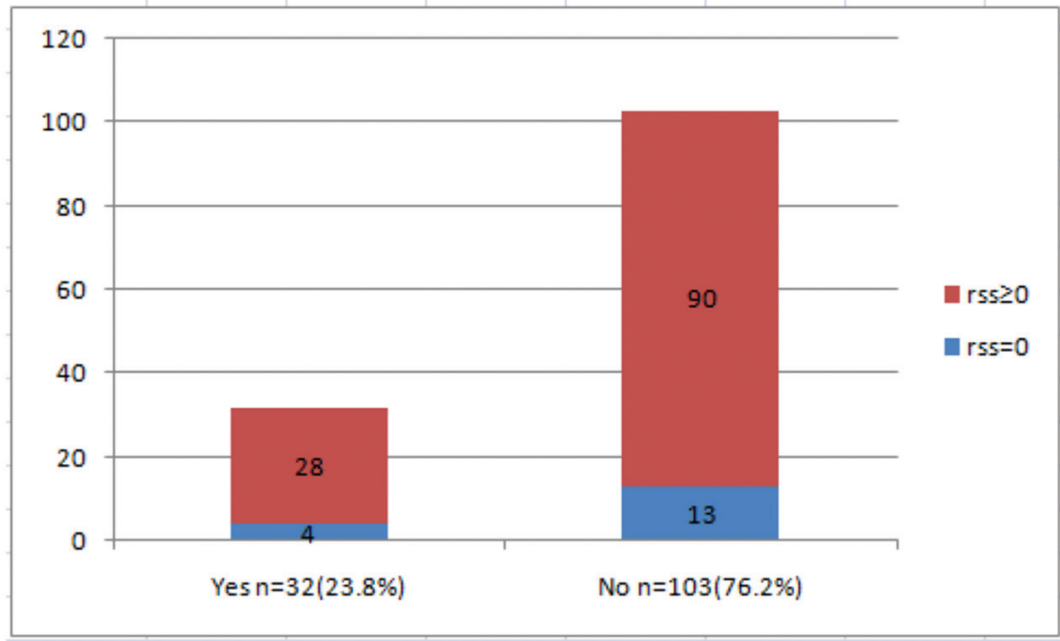

Fig. 6 Lesional calcification as a risk factor (CR vs. ICR group, $p$-value $=0.49)$. CR, complete revascularization; ICR, incomplete revascularization; RSS, residual SYNTAX Score. 


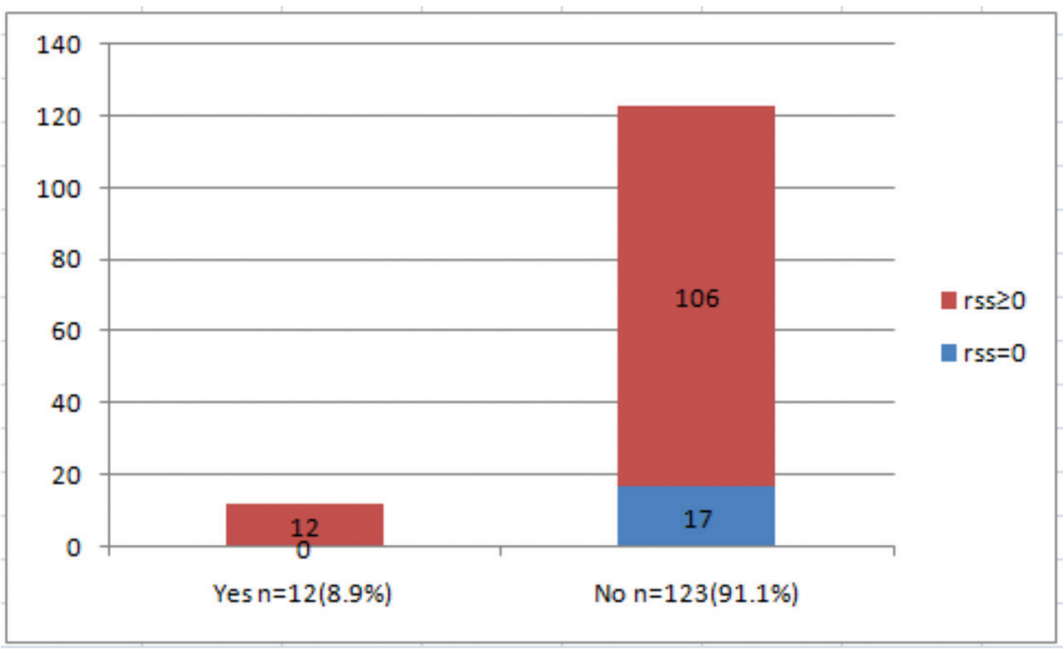

Fig. 7 Ostial disease as a risk factor (CR vs. ICR group, $p$-value = 0.09). CR, complete revascularization; ICR, incomplete revascularization; RSS, residual SYNTAX Score.

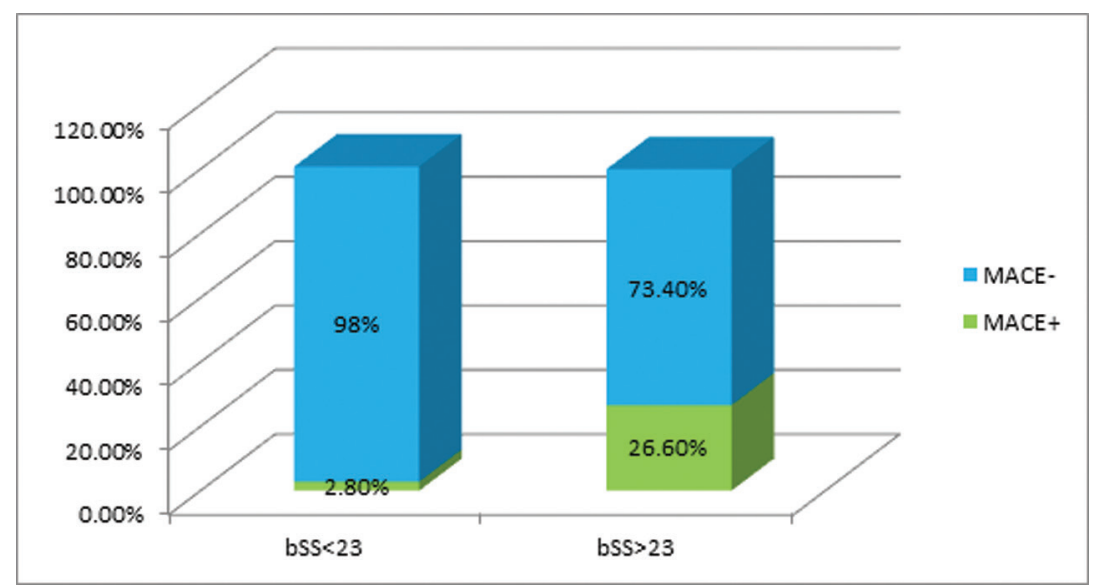

Fig. 8 Major adverse cardiac and cerebrovascular events (MACE) according to Baseline SYNTAX Score (BSS).

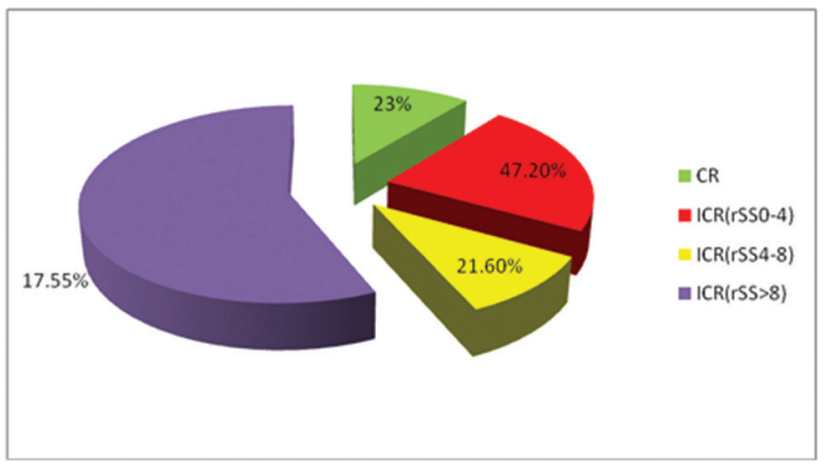

Fig. 9 Distribution of Residual SYNTAX Scores across tertiles. CR, complete revascularization; ICR, incomplete revascularization.

major epicardial vessels may directly improve long-term prognosis. ${ }^{30-34}$

The present study reconfirmed that a higher BSS was associated with higher RSS, which further is associated with more considerable morbidity and mortality. However, the RSS is based solely on angiographic quantification that cannot account for the interindividual variability related to the clinical risk factors, which are known and proven to effect long-term outcomes after revascularization with $\mathrm{PCl}$ such as elderly age, presence of LV dysfunction, and associated renal dysfunction. ${ }^{35}$

Thus, RSS added prognostic value in patients with MVCAD undergoing ICR, which supports its clinical use. We recommend that all patients with MVCAD undergoing PCI should undergo a functional assessment of the residual lesions even though they appear as anatomically significant that would translate into good clinical outcomes, which was proved in chronic kidney disease as well as obstructive sleep apnea patients also. ${ }^{36}$

However, further studies are needed to assess the anatomic versus the functional residual burden of residual coronary atherosclerosis that further helps in prognostication.

\section{Limitations}

1. Calculation of RSS could be objective. Thus, false positives and false negatives may occur.

2. Functional residual coronary atherosclerotic plaque burden, when compared with residual anatomical atherosclerotic plaque burden further, helps in prognostication, which could not be done in the present study. 


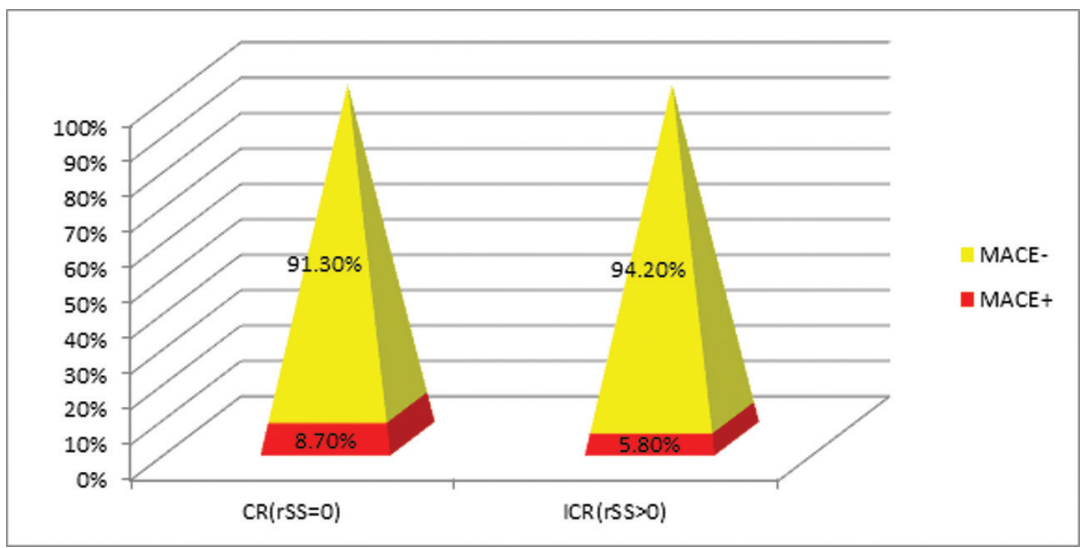

Fig. 10 Major adverse cardiac and cerebrovascular events (MACE) in complete revascularization (CR) versus incomplete revascularization (ICR) groups, $p$-value $=0.49$. The difference is not statistically significant .

\section{Conclusion}

In conclusion, severe coronary atherosclerosis (SYNTAX $\geq 23$ points) was significantly associated with an increased risk of morbidity and mortality; after PCI higher residual coronary atherosclerosis (SYNTAX $\geq 8$ points) was associated with a higher risk of morbidity compared with SYNTAX $<8$ points.

\section{Conflicts of Interest}

None declared.

\section{References}

1 Farooq V, Serruys PW, Garcia-Garcia HM, et al. The negative impact of incomplete angiographic revascularization on clinical outcomes and its association with total occlusions: the SYNTAX (Synergy Between Percutaneous Coronary Intervention with Taxus and Cardiac Surgery) trial. J Am Coll Cardiol 2013;61(3):282-294

2 Mohr FW, Morice MC, Kappetein AP, et al. Coronary artery bypass graft surgery versus percutaneous coronary intervention in patients with three-vessel disease and left main coronary disease: 5-year follow-up of the randomised, clinical SYNTAX trial. Lancet 2013;381(9867):629-638

3 Serruys PW, Morice MC, Kappetein AP, et al; SYNTAX Investigators. Percutaneous coronary intervention versus coronary-artery bypass grafting for severe coronary artery disease. N Engl J Med 2009;360(10):961-972

4 Kappetein AP, Feldman TE, Mack MJ, et al. Comparison of coronary bypass surgery with drug-eluting stenting for the treatment of left main and/or three-vessel disease: 3-year follow-up of the SYNTAX trial. Eur Heart J 2011;32(17):2125-2134

5 Ong AT, Serruys PW, Mohr FW, et al. The SYNergy between percutaneous coronary intervention with TAXus and cardiac surgery (SYNTAX) study: design, rationale, and run-in phase. Am Heart J 2006;151(6):1194-1204

6 Rosner GF, Kirtane AJ, Genereux P, et al. Impact of the presence and extent of incomplete angiographic revascularization after percutaneous coronary intervention in acute coronary syndromes: the Acute Catheterization and Urgent Intervention Triage Strategy (ACUITY) trial. Circulation 2012;125(21):2613-2620

7 De Bruyne B. Multivessel disease: from reasonably incomplete to functionally complete revascularization. Circulation 2012;125(21):2557-2559
8 Dauerman HL. Reasonable incomplete revascularization. Circulation 2011;123(21):2337-2340

9 Hannan EL, Wu C, Walford G, et al. Incomplete revascularization in the era of drug-eluting stents: impact on adverse outcomes. JACC Cardiovasc Interv 2009;2(1):17-25

10 Kim YH, Park DW, Lee JY, et al. Impact of complete angiographic revascularization after drug-eluting stent implantation or coronary artery bypass graft surgery for multivessel coronary artery disease. Circulation 2011;123:2373-2381

11 Taggart DP. Incomplete revascularization: appropriate and inappropriate. Eur J Cardiothorac Surg 2012;41(3):542-543

12 Schwartz L, Bertolet M, Feit F, et al. Impact of completeness of revascularization on long-term cardiovascular outcomes in patients with type 2 diabetes mellitus: results from the Bypass Angioplasty Revascularization Investigation 2 Diabetes (BARI 2D) Circ Cardiovasc Interv 2012;5(2):166-173

13 Gössl M, Faxon DP, Bell MR, Holmes DR, Gersh BJ. Complete versus incomplete revascularization with coronary artery bypass graft or percutaneous intervention in stable coronary artery disease. Circ Cardiovasc Interv 2012;5(4):597-604

14 Ong AT, Serruys PW. Complete revascularization: coronary artery bypass graft surgery versus percutaneous coronary intervention. Circulation 2006;114(3):249-255

15 Rastan AJ, Walther T, Falk V, et al. Does reasonable incomplete surgical revascularization affect early or long-term survival in patients with multivessel coronary artery disease receiving left internal mammary artery bypass to left anterior descending artery? Circulation 2009;120(11, Suppl):S70-S77

16 Généreux P, Palmerini T, Caixeta A, et al. Quantification and impact of untreated coronary artery disease after percutaneous coronary intervention: the residual SYNTAX (Synergy Between PCI with Taxus and Cardiac Surgery) score. J Am Coll Cardiol 2012;59(24):2165-2174

17 Wald DS, Morris JK, Wald NJ, et al; PRAMI Investigators. Randomized trial of preventive angioplasty in myocardial infarction. N Engl J Med 2013;369(12):1115-1123

18 Gershlick AH, Khan JN, Kelly DJ, et al. Randomized trial of complete versus lesion-only revascularization in patients undergoing primary percutaneous coronary intervention for STEMI and multivessel disease: the CvLPRIT trial. J Am Coll Cardiol 2015;65(10):963-972

19 Engstrøm T, Kelbæk H, Helqvist S, et al; DANAMI-3-PRIMULT Investigators. Complete revascularisation versus treatment of the culprit lesion only in patients with ST-segment elevation myocardial infarction and multivessel disease (DANAMI-3PRIMULTI): an open-label, randomised controlled trial. Lancet 2015;386(9994):665-671 
20 King SB, III. Is it form or function?: the "COURAGE” to ask. JACC Cardiovasc Interv 2014;7(2):202-203

21 Mushtaq S, Gonçalves PA, Garcia-Garcia H, et al. Long-term prognostic effect of atherosclerotic coronary burden: validation of the computed tomography-Leaman score. Circ Cardiovasc Imaging 2015;8(2):e002332

22 Farooq V, Serruys PW, Bourantas CV, et al. Quantification of incomplete revascularization and its association with fiveyear mortality in the synergy between percutaneous coronary intervention with Taxus and cardiac surgery (SYNTAX) trial validation of the residual SYNTAX score. Circulation 2013;128(2):141-151

23 Généreux P, Palmerini T, Caixeta A, et al. Quantification and impact of untreated coronary artery disease after percutaneous coronary intervention: the residual SYNTAX (Synergy Between PCI with Taxus and Cardiac Surgery) score. J Am Coll Cardiol 2012;59(24):2165-2174

24 Capodanno D, Chisari A, Giacoppo D, et al. Objectifying the impact of incomplete revascularization by repeat angiographic risk assessment with the residual SYNTAX score after left main coronary artery percutaneous coronary intervention. Catheter Cardiovasc Interv 2013;82(3):333-340

25 Hachamovitch R, Hayes SW, Friedman JD, Cohen I, Berman DS. Comparison of the short-term survival benefit associated with revascularization compared with medical therapy in patients with no prior coronary artery disease undergoing stress myocardial perfusion single photon emission computed tomography. Circulation 2003;107(23):2900-2907

26 Shaw LJ, Berman DS, Maron DJ, et al; COURAGE Investigators. Optimal medical therapy with or without percutaneous coronary intervention to reduce ischemic burden: results from the Clinical Outcomes Utilizing Revascularization and Aggressive Drug Evaluation (COURAGE) trial nuclear substudy. Circulation 2008;117(10):1283-1291

27 Davies RF, Goldberg AD, Forman S, et al. Asymptomatic Cardiac Ischemia Pilot (ACIP) study two-year follow-up: outcomes of patients randomized to initial strategies of medical therapy versus revascularization. Circulation 1997;95(8):2037-2043
28 Aggarwal V, Rajpathak S, Singh M, Romick B, Srinivas VS. Clinical outcomes based on completeness of revascularisation in patients undergoing percutaneous coronary intervention: a meta-analysis of multivessel coronary artery disease studies. EuroIntervention 2012;7(9):1095-1102

29 Head SJ, Mack MJ, Holmes DR, Jr. et al; Incidence, predictors and outcomes of incomplete revascularization after percutaneous coronary intervention and coronary artery bypass grafting: a subgroup analysis of 3-year SYNTAX data. Eur J Cardiothorac Surg 2012;41(3):535-541

30 Stefanini GG, Holmes DR Jr. Drug-eluting coronary-artery stents. N Engl J Med 2013;368(3):254-265

31 Zhang Y, Farooq V, Garcia-Garcia HM, et al. Comparison of intravascular ultrasound versus angiography-guided drug-eluting stent implantation: a meta-analysis of one randomised trial and ten observational studies involving 19,619 patients. EuroIntervention 2012;8(7):855-865

32 Werner GS, Schofer J, Sievert H, Kugler C, Reifart NJ. Multicentre experience with the BridgePoint devices to facilitate recanalisation of chronic total coronary occlusions through controlled subintimal re-entry. EuroIntervention 2011;7(2):192-200

33 Farooq V, Mamas MA, Fath-Ordoubadi F. Fraser DG. The use of a guide catheter extension system as an aid during transradial percutaneous coronary intervention of coronary artery bypass grafts. Catheter Cardiovasc Interv 2011;78(6):847-863

34 Nam CW, Mangiacapra F, Entjes R, et al. FAME Study Investigators. Functional SYNTAX score for risk assessment in multivessel coronary artery disease. J Am Coll Cardiol 2011;58(12):1211-1218

35 Capodanno D. Beyond the SYNTAX score-advantages and limitations of other risk assessment systems in left main percutaneous coronary intervention. Circ J 2013;77(5):1131-1138

36 Zeng Y, Yang S, Wang X, Fan J, Nie S, Wei Y. Prognostic impact of residual SYNTAX score in patients with obstructive sleep apnea and acute coronary syndrome: a prospective cohort study. Respir Res 2019;20(1):43 